DOI: $10.21055 / 0370-1069-2020-4-99-105$

УДК 616.98:578.2
А.Ю. Попова ${ }^{1,2}$, Е.Б. Ежлова ${ }^{1}$ Ю.В. Демина ${ }^{1,2}$, А.К. Носков ${ }^{3}$, Е.В. Ковалев ${ }^{4}$ О.С. Чемисова ${ }^{3}$, Т.И. Твердохлебова ${ }^{5}$, Н.В. Павлович ${ }^{3}$, С.О. Водопьянов ${ }^{3}$, М.В. Цимбалистова ${ }^{3}$, Н.Е. Гаевская ${ }^{3}$, С.Ф. Воловикова ${ }^{3}$, С.И. Стенина ${ }^{3}$, Е.Н. Гудуева ${ }^{3}$, М.М. Сагакянц ${ }^{3}$ А.В. Алешукина ${ }^{5}$, С.С. Слись ${ }^{4}$

\section{ОСОБЕННОСТИ ЭТИОЛОГИИ ВНЕБОЛЬНИЧНЫХ ПНЕВМОНИЙ, АССОЦИИРОВАННЫХ C COVID-19}

\begin{abstract}
${ }^{1}$ Федеральная служба по надзору в сфере защиты прав потребителей и благополучия человека, Москва, Российская Федерация; ${ }^{2}$ Российская медицинская академия непрерывного профессионального образования, Москва, Российская Федерация;

${ }^{3}$ ФКУЗ «Ростовский-на-Дону научно-исследовательский противочумный институт», Ростов-на-Дону, Российская Федераичя;

${ }^{4}$ Управление Роспотребнадзора по Ростовской области, Ростов-на-Дону, Российская Федерация; 5 ФБУН «Ростовский научноисследовательский институт микробиологии и паразитологии», Ростов-на-Дону, Российская Федерация
\end{abstract}

Цель исследования - сравнительное изучение этиологической структуры внебольничных пневмоний у SARSCoV-2 «+» и SARS-CoV-2 «-» больных, обратившихся за помощью в медицинские организации Ростовской области. Материалы и методы. Исследовали биологический материал (мазки из носоглотки и мокроту) от 508 пациентов с диагнозом «внебольничная пневмония», находившихся на амбулаторном лечении или в стационарах г. Ростова-на-Дону. Верификация респираторных вирусов, включая PHK SARS-CoV-2, а также M. pneumoniae, C. pneumoniae, L. pneumophila выполнена методом полимеразной цепной реакции в мазках носоглотки $(\mathrm{n}=508)$. Бактериологический анализ мокроты проводили с использованием дифференциально-диагностических сред, идентификацию выделенных патогенов осуществляли с помощью времяпролетной масс-спектрометрии на прибope Autoflex (Bruker Daltonics, Германия) с программным обеспечением BioTyper 3,0. Результаты и обсуждение. В период распространения новой коронавирусной инфекции в Ростовской области основным этиологическим агентом внебольничных пневмоний является новый коронавирус SARS-CoV-2. Особенностью внебольничных пневмоний (ВП) у пациентов с лабораторно подтвержденным COVID-19 является более высокая частота микстинфекций как вирусной, так и бактериальной этиологии. На фоне выявления у пациентов с BП PHК SARS-CoV-2 зарегистрированы случаи обнаружения коронавирусов других типов (HKU-1, OC43, HL-63 или 229E). Наиболее часто этиологическим агентом ВП бактериальной природы являлись бактерии рода Streptococcus как у пациентов с ВП, ассоциированной с COVID-19, так и у пациентов с отрицательным результатом на SARS-CoV-2. Коронавирусные больные представляют группу высокого риска по развитию микотических поражений легких.

Ключевые слова: COVID-19, внебольничная пневмония, виды бактерий, респираторные вирусы, Ростовская область.

Корреспондирующий автор: Носков Алексей Кимович, е-mail: plague@aaanet.ru.

Для цитирования: Попова А.Ю., Ежлова Е.Б., Демина Ю.В., Носков А.К., Ковалев Е.В., Чемисова О.С., Твердохлебова Т.И., Павлович Н.В., Водопьянов С.О., Цимбалистова М.В., Гаевская Н.Е., Воловикова С.Ф., Стенина С.И., Гудуева Е.Н., Сагакянц М.М., Алешукина А.В., Слись С.С. Особенности этиологии внебольничных пневмоний, ассоциированных с COVID-19. Проблемы особо опасных инфекций. 2020; 4:99-105. DOI: 10.21055/0370-1069-2020-4-99-105

Поступила 01.12.20. Принята к публ. 23.12.20.

A.Yu. Popova ${ }^{1,2}$, E.B. Ezhlova ${ }^{1}$, Yu.V. Demina ${ }^{1,2}$, A.K. Noskov ${ }^{3}$, E.V. Kovalev ${ }^{4}$, O.S. Chemisova ${ }^{3}$, T.I. Tverdokhlebova ${ }^{5}$, N.V. Pavlovich ${ }^{3}$, S.O. Vodop'yanov ${ }^{3}$, M.V. Tsimbalistova ${ }^{3}$, N.E. Gaevskaya ${ }^{3}$, S.V. Volovikova ${ }^{3}$, S.I. Stenina ${ }^{3}$, E.N. Gudueva ${ }^{3}$, M.M. Sagakyants ${ }^{3}$, A.V. Aleshukina ${ }^{5}$, S.S. Slis ${ }^{4}$

\title{
Features of Etiology of Community-Acquired Pneumonia Associated with COVID-19
}

'Federal Service for Surveillance on Consumer' Rights Protection and Human Welfare, Moscow, Russian Federation;

${ }^{2}$ Russian Medical Academy of Continuing Professional Education, Moscow, Russian Federation;

${ }^{3}$ Rostov-on-Don Anti-Plague Research Institute, Rostov-on-Don, Russian Federation;

${ }^{4}$ Rospoptrebnadzor Administration in the Rostov Region, Rostov-on-Don, Russian Federation;

${ }^{5}$ Rostov Research Institute of Microbiology and Parasitology, Rostov-on-Don, Russian Federation

Abstract. Objective: comparative study of the etiological structure of community-acquired pneumonia in SARSCoV-2 “+”and SARS-CoV-2 ““_“ patients who sought help from medical organizations in the Rostov Region. Materials and methods. Biological material from 508 patients diagnosed with community-acquired pneumonia who were on outpatient treatment or in hospitals in Rostov-on-Don was studied. Verification of respiratory viruses, including SARS-CoV-2 RNA, as well as M. pneumoniae, C. pneumoniae, and L. pneumophila was performed by polymerase chain reaction in nasopharyngeal smears. Bacteriological analysis of sputum was carried out using differential diagnostic media, identification of isolated pathogens was carried out using time-of-flight mass spectrometry on Autoflex (Bruker Daltonics) with BioTyper 3.0 software. Results and discussion. During the spread of a new coronavirus infection in the Rostov Region, the main etiological agent of community-acquired pneumonia is the new SARS-CoV-2 coronavirus. Specific character of pneumonia in patients with laboratory-confirmed COVID-19 is a higher incidence of mixed infection of both viral and bacterial etiology. Against the background of detection of a new coronavirus infection in patients with pneumonia, cases of detection of other types of coronaviruses have been registered (HKU-1,OC43, HL-63 and 229E). The most common etiological agent of bacterial pneumonia in patients was Streptococcus spp., both in patients with COVID-19-associated 
pneumonia and in patients who tested negative for SARS-CoV-2. Coronavirus patients represent a high risk group for the development of mycotic lung lesions.

Key words: COVID-19, community-acquired pneumonia, types of bacteria, respiratory viruses, Rostov Region.

Conflict of interest: The authors declare no conflict of interest.

Corresponding author: Aleksey K. Noskov, e-mail: plague@aaanet.ru.

Citation: Popova A.Yu., Ezhlova E.B., Demina Yu.V., Noskov A.K., Kovalev E.V., Chemisova O.S., Tverdokhlebova T.I., Pavlovich N.V., Vodopyanov S.O. Tsimbalistova M.V., Gaevskaya N.E., Volovikova S.V., Stenina S.I., Gudueva E.N., Sagakyants M.M., Aleshukina A.V., Slis' S.S. Features of Etiology of CommunityAcquired Pneumonia Associated with COVID-19. Problemy Osobo Opasnykh Infektsii [Problems of Particularly Dangerous Infections]. 2020; 4:99-105. (In Russian). DOI: $10.21055 / 0370-1069-2020-4-99-105$

Received 01.12.20. Accepted 23.12.20.

Popova A.Yu., ORCID: https://orcid.org/0000-0002-4315-5307 Noskov A.K., ORCID: https://orcid.org/0000-0003-0550-2221 Kovalev E.V., ORCID: https://orcid.org/0000-0002-0840-4638 Chemisova O.S., ORCID: https://orcid.org/0000-0002-4059-2878 Tverdokhlebova T.I., ORCID: https://orcid.org/0000-0002-3912-0291 Pavlovich N.V., ORCID: https://orcid.org/0000-0001-8287-4294 Vodopyanov S.O., ORCID: https://orcid.org/0000-0003-4336-0439 Tsimbalistova M.V., ORCID: https://orcid.org/0000-0002-4091-649X

Внебольничные пневмонии (ВП) представляют серьезную проблему инфекционной патологии человека и являются одной из ведущих причин смерти от инфекционных болезней. Внебольничная пневмония - острое заболевание, возникшее во внебольничных условиях (вне стационара или позднее 4 недель после выписки из него), сопровождающееся симптомами инфекции нижних отделов дыхательных путей [1]. Согласно данным статистических материалов Федеральной службы по надзору в сфере защиты прав потребителей и благополучия человека (Форма 2) за 2019 г., заболеваемость ВП в РФ в 2018 г. составила 492,2 на 100 тыс. населения, что на 19,1\% выше по сравнению с 2017 г. Ведущими возбудителями ВП являются Streptococcus pneumoniae, Haemophilus influenzae, бактерии семейства EnterobacteriaceaeKlebsiella pneumoniae, Escherichia coli и др., Staphylococcus aureus [1]. К известным атипичным бактериальным возбудителям ВП относятся такие микроорганизмы, как Mycoplasma pneumoniae, Chlamydophila pneumoniae, Legionella pneumophila, Chlamydophila psittaci и Coxiella burnetii [2]. Такие условно патогенные бактерии - представители резидентной микрофлоры носоглотки человека, как Streptococcus viridans, коагулазанегативные стафилококки, Enterococcus spp., Neisseria spp., Candida spp., могут иметь этиологическое значение только при их неконтролируемом размножении на фоне резкого снижения иммунного статуса организма. Их выделение в незначительных количествах из мокроты у пациентов без выраженного иммунодефицита с высокой степенью вероятности может свидетельствовать о контаминации материала микрофлорой верхних отделов дыхательных путей. Возбудителями ВП могут быть и респираторные вирусы, наиболее часто вирусы гриппа, коронавирусы, риносинцитиальный вирус (РС-вирус), метапневмовирус и бокавирус человека [1]. При ВП может иметь место ко-инфекция двумя и более возбудителями, вызванная как ассоциацией различных бактериальных возбудителей, так и их сочетанием с респираторными вирусами. Частота встречаемости ВП, вызванной ассоциацией возбудителей, варьирует от 3 до $40 \%$ [3].

\begin{abstract}
Gaevskaya N.E., ORCID: https://orcid.org/0000-0002-0762-3628 Volovikova S.V., ORCID: https://orcid.org/0000-0003-3064-8177 Stenina S.I., ORCID: https://orcid.org/0000-0003-4879-6717 Gudueva E.N., ORCID: https://orcid.org/0000-0002-6114-9891 Sagakyants M.M., ORCID: https://orcid.org/0000-0001-8235-3288 Aleshukina A.V., ORCID: https://orcid.org/0000-0002-9797-2441 Slis' S.S., ORCID: https://orcid.org/0000-0002-2649-8949
\end{abstract}

Пандемия новой коронавирусной инфекции сопровождается высоким уровнем заболеваемости ВП, с большой долей осложненных и затяжных случаев. Известно, что вирусы вызывают нарушения работы иммунной системы, что делает людей более восприимчивыми к другим патогенам [4]. G. Zahariadis et al. в 2006 г., основываясь на результатах серологических исследований пациентов, перенесших ОРВИ, выявили случаи острой или недавней инфекции C.pneumoniae (30\%) или M.pneumoniae (9\%) [5]. Многоцентровое ретроспективное когортное исследование пациентов с тяжелым течением Ближневосточного респираторного синдрома, вызванного коронавирусом (БВРС-КоВ), показало, что 18 и $5 \%$ имели бактериальные и вирусные коинфекции соответственно [6].

Предыдущие исследования показали, что коронавирус наносит серьезный удар по иммунной системе человека. Например, одним из наиболее распространенных симптомов у пациентов с COVID-19 является временное или стойкое снижение уровня лимфоцитов в крови. Разрушение иммунных клеток вирусом SARS-CoV-2 делает пациентов уязвимыми к вторичным бактериальным инфекциям. Пневмония у пациентов с COVID-19 отличается от SARS-CoV-2негативной внебольничной пневмонии [7].

C.-C. Lai etal. (2020 г.)провели анализ лабораторных данных о вторичных инфекциях при COVID-19, опубликованных исследователями Китая, США, Сингапура и Италии [8]. При обследовании 18 пациентов в Сингапуре ни у одного из них не было сопутствующих или вторичных инфекций. Напротив, результаты других десяти исследовательских групп выявили распространенность вторичных осложнений, ассоциированных с COVID-19, частота которых колебалась от 0,6 до 45,0 \%. В других шести независимых исследованиях зарегистрированы осложнения, обусловленные присоединением бактериальной ко-инфекции, этиологические агенты которых включали M. pneumoniae, L. pneumophila, S. pneumoniae и K. pneumoniae. В литературе имеются также сообщения о вирусных сопутствующих ко-инфекциях; риновирус/энтеровирус и грипп А являются наиболее 
распространенными ассоциантами. Кроме того, в качестве сопутствующих патогенов зарегистрированы коронавирус, респираторно-синцитиальный вирус, парагрипп, метапневмовирус и вирус гриппа В [8]. В исследовании N. Chen et al. (2020 г.) 99 пациентов с COVID-19 у 4,0\% выявлены грибковые сопутствующие инфекции, включая Candida albicans и Candida glabrata [9]. М.В. Стуловой с соавт. (2020 г.) при исследовании пациентов с ВП, ассоциированной с COVID-19, наиболее частыми бактериальными агентами определены S. pneumoniae (70,0\%), Streptococcus agalactiae (10,0\%), S. pneumoniae + S. aureus $(6,6 \%), S$. pneumoniae + Pseudomonas aeruginosa $(13,3 \%)$ [10].

По данным Управления Роспотребнадзора по Ростовской области, за первые семь месяцев 2020 г. в области зарегистрирован 13621 случай ВП - 324,1 на 100 тыс. населения, что в 1,8 раза выше аналогичного периода 2019 г. и выше среднемноголетнего уровня так же в 1,8 раза. За семь месяцев 2020 г. 253 случая пневмонии завершились летальным исходом (за семь месяцев 2019 г. - 36), летальность увеличилась в 7,1 раза $(6,0$ против 0,9$)$. Во всех случаях имелся отягощенный преморбидный фон: ишемическая болезнь сердца, сахарный диабет, ожирение, алкоголизм и т.д.; диагноз COVID-19 подтвержден в 225 случаях (88,9\%).

Неотъемлемой частью диагностики ВП и основой адекватного лечения, снижения летальности является определение этиологического агента, а в случае выявления возбудителя бактериальной природы - определение его чувствительности к антибиотикам для дальнейшей корректировки этиотропной терапии.

Целью настоящей работы являлось сравнительное изучение этиологической структуры внебольничных пневмоний у SARS-CoV-2 «+» и SARSCoV-2 «-» больных, обратившихся за помощью в медицинские организации Ростовской области.

\section{Материалы и методы}

В период 6-23 августа 2020 г. обследовано 508 больных внебольничной пневмонией, находившихся в стационарах или на амбулаторном лечении. Критерии включения в исследование: возраст старше 18 лет, установленный диагноз внебольничной пневмонии (J 18.9) согласно Российским национальным рекомендациям по внебольничной пневмонии (2019), информированное согласие пациента на участие в исследовании.

Материал для исследования: мазки из носоглотки и мокрота. Сбор, транспортирование и исследование биоматериала соответствовали требованиям нормативной документации МР 4.2.0114-16 и МУК 4.2.3115-13.

Верификация респираторных вирусов, включая PHK SARS-CoV-2, а также M.pneumoniae, C. pneumoniae, L. pneumophila выполнена методом полимеразной цепной реакции в мазках носоглотки $(\mathrm{n}=508)$. Сравнительный анализ результативности обнаружения PHK SARS-CoV-2 проведен путем параллельного ПЦР-исследования мазков носоглотки и мокроты $(\mathrm{n}=406)$. Исследование клинического материала осуществляли при помощи коммерческих наборов реагентов: «РИБО-преп», «Реверта-L», «АмплиСенс ОРВИ-скрин-FL», «АмплиСенс Influenza virus A/B-FL», «АмплиСенс Мусорlasma pneumoniae / Chlamydophila pneumoniae-FL», «АмплиСенс Legionella pneumophila-FL» (ФБУН «ЦНИИЭ», Россия), «Вектор-ПЦРрв-2019-nCoV-RG» (ГНЦ «Вектор», Россия).

Проведено микроскопическое исследование мокроты, окрашенной по Граму $(\mathrm{n}=508)$, посев мокроты с определением концентрации возбудителя $(\mathrm{n}=508)$. Клинически значимыми считали микроорганизмы, выделенные из мокроты в количестве $\geq 10^{5} \mathrm{KOЕ/мл.} \mathrm{Идентификацию} \mathrm{выделенных} \mathrm{штам-}$ мов бактерий осуществляли с помощью времяпролетной масс-спектрометрии на приборе Autoflex (Bruker Daltonics, Германия) с программным обеспечением BioTyper 3,0. Уровень достоверности (Score) выше 2,3 свидетельствовал о точной видовой идентификации.

Анализ данных проведен с помощью пакета статистических программ STATISTICA версия 10.0 (StatSoft Inc., США). Сравнение количественных показателей выполнено с применением критерия Стьюдента. Различия считались статистически значимыми при $\mathrm{p}<0,05$.

\section{Результаты и обсуждение}

На исследование поступили пробы биологического материала от 508 больных с диагнозом «внебольничная пневмония» (J 18.9), в том числе от женщин - 283 (55,7 \%), мужчин - 225 (44,3 \%). Возраст пациентов составлял от 21 года до 94 лет (медиана 61 год). В результате исследования показано, что частота случаев ВП увеличивается пропорционально возрасту пациентов. Так, 73,6 \% случаев ВП зарегистрировано у лиц старше 50 лет, при этом наибольшее $(29,1 \%)$ число заболевших отмечено среди пациентов от 60 до 69 лет (табл. 1).

Среди обследованных 412 (81,1\%) пациентов госпитализированы в медицинские организации г. Ростова-на-Дону, 96 (18,9 \%) - находились на амбулаторном лечении. Наибольшее число (69,9\%) госпитализаций пациентов пришлось на 3-10-е сутки после начала заболевания независимо от выявления SARS-CoV-2.

С целью оценки результативности обнаружения РНК нового коронавируса в зависимости от вида клинического материала параллельно исследованы в ПЦР пробы мазков из носоглотки и мокроты у 406 пациентов (табл. 2). PHК вируса SARS-CoV-2 обнаружена в 289 (71,2 \%) образцах, из них положительный результат получен только в мазках из носоглотки в 
Таблица 1 / Table 1

Распределение по возрасту пациентов с внебольничной пневмонией

Age structure of patients with community-acquired pneumonia

\begin{tabular}{|c|c|c|c|c|c|c|c|}
\hline \multirow{2}{*}{$\begin{array}{c}\text { Возрастная } \\
\text { группа } \\
\text { Age group }\end{array}$} & \multicolumn{2}{|c|}{$\begin{array}{c}\text { SARS-CoV-2 «+»» } \\
(\mathrm{n}=307)\end{array}$} & \multicolumn{2}{|c|}{$\begin{array}{l}\text { SARS-CoV-2 «-»» } \\
\quad(n=201)\end{array}$} & \multicolumn{2}{|c|}{$\begin{array}{c}\text { Всего } \\
\text { Total }(n=508)\end{array}$} & \multirow{2}{*}{$\mathrm{p}$} \\
\hline & $\begin{array}{l}\text { абс. } \\
\text { abs. }\end{array}$ & $\%$ & $\begin{array}{l}\text { абс. } \\
\text { abs. }\end{array}$ & $\%$ & $\begin{array}{l}\text { aбc. } \\
\text { abs. }\end{array}$ & $\%$ & \\
\hline $\begin{array}{l}18-29 \text { лет } \\
18-29 \text { years }\end{array}$ & 10 & 1,97 & 11 & 2,16 & 21 & 4,13 & $>0,05$ \\
\hline $\begin{array}{l}\text { 30-39 лет } \\
30-39 \text { years }\end{array}$ & 27 & 5,31 & 14 & 2,76 & 41 & 8,07 & $>0,05$ \\
\hline $\begin{array}{l}40-49 \text { лет } \\
40-49 \text { years }\end{array}$ & 39 & 7,67 & 33 & 6,50 & 72 & 14,17 & $>0,05$ \\
\hline $\begin{array}{l}50-59 \text { лет } \\
50-59 \text { years }\end{array}$ & 58 & 11,42 & 45 & 8,85 & 103 & 20,27 & $>0,05$ \\
\hline $\begin{array}{l}\text { 60-69 лет } \\
60-69 \text { years }\end{array}$ & 91 & 17,91 & 57 & 11,22 & 148 & 29,13 & $>0,05$ \\
\hline $\begin{array}{l}>70 \text { лет } \\
>70 \text { years }\end{array}$ & 82 & 16,14 & 41 & 8,07 & 123 & 24,21 & $>0,05$ \\
\hline $\begin{array}{l}\text { Bcezo } \\
\text { Total }\end{array}$ & 307 & 60,43 & 201 & 39,57 & 508 & 100 & $<0,01$ \\
\hline
\end{tabular}

Примечание: $\mathrm{n}$ - количество наблюдений; $\mathrm{p}$ - статистическая значимость различий в группах SARS-CoV-2 «+» и SARS-CoV-2 «-».

Note: $n$ is the number of observations; $p$ - statistical significance of differences in groups SARS-CoV-2 «+» and SARS-CoV-2 «-».

182 (44,8 \%) случаях, только в мокроте - в 23 (5,7\%). Вирус идентифицирован и в мазках носоглотки, и в мокроте у 84 (20,7 \%) пациентов. Низкая частота выявления PHK SARS-CoV-2 в мокроте может быть обусловлена как непродуктивным кашлем, характерным для вирусной пневмонии, так и погрешностями отбора материала. Учитывая отсутствие статистически значимых различий результатов, полученных в образцах «мазок» и «мазок + мокрота» (соответственно 266 и 289 из 406, p>0,05), исследование мазков носоглотки на наличие PHK SARS-CoV-2 можно считать репрезентативным.

Общее число пациентов с положительным тестом на SARS-CoV-2 составило 307 из 508 исследованных (60,4\%). Доля больных с COVID-19 колебалась от 47,6 до 66,7 \%, в зависимости от возрастной группы, однако статистически достоверных различий между ними не выявлено $(\mathrm{p}>0,05)$. При этом у госпитализированных пациентов лабораторно подтвержденных случаев COVID-19 в 1,3 раза больше, чем при амбулаторном лечении (соответственно 63,3 и 47,9\%, p<0,01). В зависимости от выявления PHK SARS-CoV-2 сформированы группы исследования: 1-я группа (n=307) - пациенты с внебольничной пневмонией, вирус идентифицирован (SARS-CoV-2 «+»), 2-я группа (n=201) - пациенты с внебольничной пневмонией, вирус не идентифицирован (SARS-CoV-2 «-»).

Результаты исследования клинического материала на наличие других возбудителей инфекций дыхательных путей вирусной природы представлены в табл. 3. У 12,0 \% пациентов (61 человек) выявлены коронавирусы типов HKU-1, OC43, HL-63 или 229E (3,3 \% от всех исследованных проб), рино-
Таблица 2 / Table 2

Сравнительный анализ результативности ПЦР-исследования на SARS-CoV-2 при внебольничных пневмониях

Comparative analysis of the effectiveness of PCR research on SARS-CoV-2

\begin{tabular}{|c|c|c|c|}
\hline $\begin{array}{l}\text { Вид материала } \\
\text { Type of material }\end{array}$ & $\begin{array}{c}\text { Количество } \\
\text { исследованных } \\
\text { проб, абс. } \\
\text { Number } \\
\text { of samples } \\
\text { examined, abs. }\end{array}$ & $\begin{array}{c}\text { Количество } \\
\text { положительных } \\
\text { проб, абс. } \\
\text { Number } \\
\text { of positive } \\
\text { samples, abs. } \\
\end{array}$ & \begin{tabular}{|c} 
Доля \\
положительных \\
проб, \% \\
Percentage \\
of positive \\
samples, \% \\
\end{tabular} \\
\hline $\begin{array}{l}\text { Мазок из носоглотки } \\
\text { Nasopharyngeal swab }\end{array}$ & 406 & 266 & 65,5 \\
\hline $\begin{array}{l}\text { Мокрота } \\
\text { Sputum }\end{array}$ & 406 & 107 & 26,4 \\
\hline $\begin{array}{l}\text { Мазки + мокрота } \\
\text { (хотя бы один } \\
\text { результат } \\
\text { положителен) } \\
\text { A swab + sputum } \\
\text { (at least one result is } \\
\text { positive) }\end{array}$ & 406 & 289 & 71,2 \\
\hline
\end{tabular}

Примечание. Статистическая значимость различий в группах: а) «мазок из носоглотки» и «мокрота» $(\mathrm{p}<0,01)$; б) «мазок из носоглотки» и «мазки + мокрота» (р>0,05); в) «мокрота» и «мазки + мокрота» $(\mathrm{p}<0,01)$.

Note. Statistical significance of differences in groups: a) "nasopharyngeal swab" and "sputum" (p <0.01); b) "nasopharyngeal swab" and "smears + sputum" $(p>0.05) ; c)$ "sputum" and "smears + sputum" $(p<0.01)$.

вирусы (2,4 \%), вирус парагриппа 2-го типа (2,0 \%). Не зарегистрированы положительные результаты при исследовании на вирус гриппа типов А и В, что связано с летним сезоном. Среди пациентов с положительным результатом на SARS-CoV-2 вирусные микст-инфекции обнаружены у 31 (10,1\%) пациента. В группе с отрицательным результатом на SARS-CoV-2 доля проб с установленным возбудителем вирусной этиологии составила 30 (14,9\%). Статистически достоверных различий в обнаружении респираторных вирусов у пациентов SARSCoV-2 «+» и SARS-CoV-2 «-» не выявлено ( $>>0,05)$. Однако обращает на себя внимание тот факт, что у 25 (8,1 \%) пациентов SARS-CoV-2 «+» выявлена acсоциация двух, у 5 (1,6 \%) пациентов - трех, в одном случае - четырех этиологических агентов вирусной природы. Преимущественно зарегистрирована микст-инфекция «SARS-CoV-2 + риносинцитиальный вирус», «SARS-CoV-2 + коронавирус других типов» (по 6 пациентов). При внебольничных пневмониях с отрицательным результатом на SARS-CoV-2 одновременное сочетание двух вирусных возбудителей обнаружено лишь у 4 (1,99\%) пациентов. Таким образом, у пациентов с внебольничной пневмонией и лабораторно подтвержденным COVID-19 выше частота выявления инфекции полиэтиологического характера. Нельзя исключить, что первоначально коронавирус выступает триггером резкой иммуносупрессии организма, на фоне которой присоединяются другие, возможно, менее агрессивные ассоцианты вирусной природы.

У $299(58,9 \%)$ пациентов с внебольничной пневмонией выявлены возбудители бактериальной и грибковой природы 36 видов (табл. 4). Наиболее 
Этиологический спектр возбудителей вирусной природы Etiological spectrum of viral pathogens

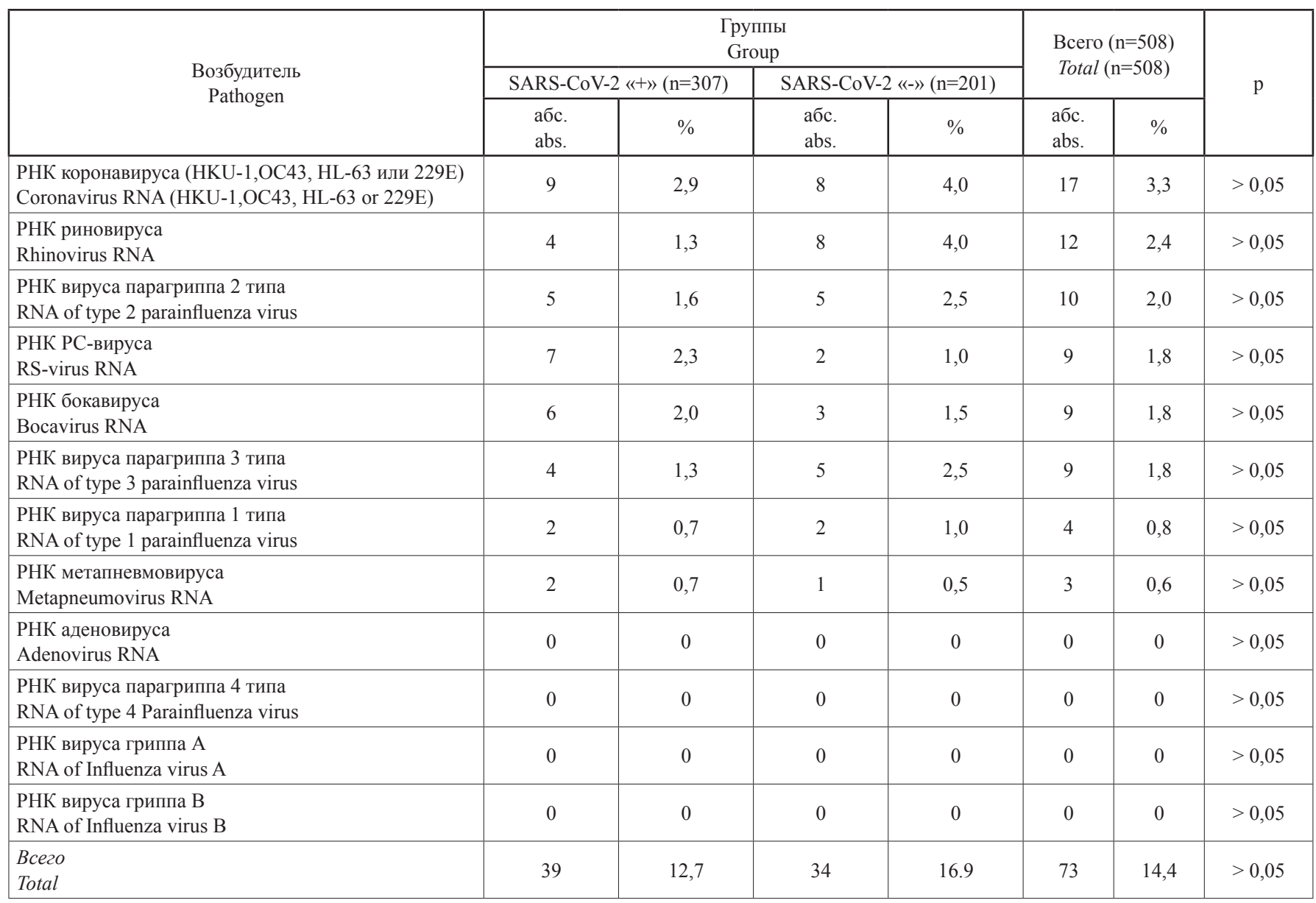

При мечание: $\mathrm{n}$ - количество наблюдений; $\mathrm{p}$ - статистическая значимость различий в группах SARS-CoV-2 «+» и SARS-CoV-2 «-».

Note: $n$ is the number of observations; $p$ - statistical significance of differences in groups SARS-CoV-2 «+» and SARS-CoV-2 «-».

частым этиологическим агентом ВП бактериальной природы являлись бактерии рода Streptococcus, которые обнаружены у 148 (29,1\%) пациентов, S. pneumoniae определен в качестве этиологического агента у 15 (5,4\%) SARS-CoV-2 «+» и у 12 (5,5\%) SARS-CoV-2 «-» пациентов. Среди других представителей стрептококков наиболее высокий удельный вес составили культуры S. viridans, выделенные у $60(19,5 \%)$ пациентов с COVID-19 и у 24 (11,9\%) пациентов с отрицательным результатом на новую коронавирусную инфекцию $(\mathrm{p}<0,05)$.

Достоверно более частыми бактериальными этиологическими агентами ВП у пациентов с отрицательным результатом исследования на SARS-CoV-2 являлись S. mitis, S. oralis, S. salivarius, S. parasanguinis, Rothia mucilaginosa, Neisseria meningitidis, N. mucosa.

В обеих группах пациентов (SARS-CoV-2 «+» и SARS-CoV-2 «-») в небольшом количестве случаев c помощью бактериологического метода изолировали различные плазмокоагулирующие (S. aureus) и некоагулирующие (S. epidermidis) стафилококки. Однако обращает на себя внимание тот факт, что если у больных с отрицательным результатом на SARS-CoV-2 стафилококковое поражение легких (S. aureus) сопровождалось, по данным микроскопии, выраженным нейтрофильным лейкоцитозом, то у SARS-CoV-2 «+» больных наблюдалось отсутствие какой-либо лейкоцитозной реакции. Эта закономерность зарегистрирована и в случае выявления других бактериальных возбудителей: K pneumoniae, P. aeruginosa и др. Это еще раз свидетельствует в пользу того, что коронавирус резко подавляет иммунную систему макроорганизма.

Согласно имеющимся в нашем распоряжении данным, лечение антибактериальными препаратами на момент обследования проводилось у 29 \% пациентов. Возможно, на фоне антибиотикотерапии у $86(16,9 \%)$ пациентов выделены дрожжи p. Candida в диагностических количествах $\left(\geq 10^{4}\right)$. Y SARS-CoV-2 «+» больных дрожжевая микрофлора выявлена в 20,2 \% случаев, у SARS-CoV-2 «-» больных $-11,9 \%(\mathrm{p}<0,05)$.

Не выявлено зависимости удельного веса пациентов с микст-инфекциями от дня госпитализации после начала заболевания. Отсутствовали различия 
Этиологически значимые микроорганизмы, изолированные из мокроты больных внебольничными пневмониями Etiologically significant microorganisms isolated from sputum of patients with community-acquired pneumonia

\begin{tabular}{|c|c|c|c|c|c|c|c|c|}
\hline Вид м & рганизма & & & SARS-C & $(\mathrm{n}=307)$ & SARS-C & $(\mathrm{n}=201)$ & \\
\hline Microo & m species & абс. & 0 & абс. & 0 & абс. & 0 & $\mathrm{p}$ \\
\hline & pneumoniae & 28 & 5,5 & 17 & 5,4 & 12 & 5,5 & $>0,05$ \\
\hline & viridans & 84 & 16,5 & 60 & 19,5 & 24 & 11,9 & $<0,05$ \\
\hline & acidominimus & 1 & 0,2 & 0 & 0 & 1 & 0,5 & $>0,05$ \\
\hline & agalactiae & 1 & 0,2 & 0 & 0 & 1 & 0,5 & $>0,05$ \\
\hline Streptococcus & infantis & 1 & 0,2 & 0 & 0 & 1 & 0,5 & $>0,05$ \\
\hline & mitis & 8 & 1,6 & 0 & 0 & 8 & 4,0 & $<0,01$ \\
\hline & oralis & 8 & 1,6 & 0 & 0 & 8 & 4,0 & $<0,01$ \\
\hline & salivarius & 11 & 2,2 & 0 & 0 & 11 & 5,5 & $<0,001$ \\
\hline & parasanguinis & 6 & 1,2 & 0 & 0 & 6 & 3,0 & $<0,01$ \\
\hline & albicans & 86 & 16,9 & 62 & 20,2 & 24 & 11,9 & $<0,05$ \\
\hline & krusei & 4 & 0,8 & 4 & 1,3 & 0 & 0,0 & $>0,05$ \\
\hline & kefir & 1 & 0,2 & 0 & 0 & 1 & 0,5 & $>0,05$ \\
\hline Candida & tropicalis & 21 & 4,1 & 16 & 5,2 & 5 & 2,5 & $>0,05$ \\
\hline & guilliermondii & 1 & 0,2 & 1 & 0,3 & 0 & 0,0 & $>0,05$ \\
\hline & lusitaniae & 1 & 0,2 & 0 & 0,0 & 1 & 0,5 & $>0,05$ \\
\hline Geotrichum cap & & 2 & 0,4 & 2 & 0,7 & 0 & 0,0 & $>0,05$ \\
\hline & meningitidis & 5 & 1,0 & 0 & 0 & 5 & 2,5 & $<0,01$ \\
\hline & flavescens & 26 & 5,1 & 11 & 3,6 & 15 & 7,5 & $>0,05$ \\
\hline & subflavescens & 6 & 1,2 & 5 & 1,6 & 1 & 0,5 & $>0,05$ \\
\hline Neisseria & flava & 1 & 0,2 & 1 & 0,3 & 0 & 0,0 & $>0,05$ \\
\hline & subflava & 1 & 0,2 & 1 & 0,3 & 0 & 0,0 & $>0,05$ \\
\hline & sicca & 4 & 0,8 & 3 & 1,0 & 1 & 0,5 & $>0,05$ \\
\hline & mucosa & 3 & 0,6 & 0 & 0 & 3 & 1,5 & $<0,05$ \\
\hline Rothia mucilagi & & 16 & 3,2 & 3 & 1,0 & 13 & 6,5 & $<0,01$ \\
\hline & aureus & 51 & 10,0 & 36 & 11,7 & 15 & 7,5 & $>0,05$ \\
\hline Stanhylococour & capitis & 2 & 0,4 & 0 & 0 & 2 & 1,0 & $>0,05$ \\
\hline Staphylococcus & epidermidis & 2 & 0,4 & 0 & 0 & 2 & 1,0 & $>0,05$ \\
\hline & haemolitycus & 4 & 0,8 & 0 & 0 & 4 & 2,0 & $<0,05$ \\
\hline Escherichia coli & & 6 & 1,2 & 6 & 2,0 & 0 & 0,0 & $<0,05$ \\
\hline Enterococcus fa & & 9 & 1,8 & 5 & 1,6 & 4 & 2,0 & $>0,05$ \\
\hline Stenotrophomon & tophilia & 2 & 0,4 & 1 & 0,3 & 1 & 0,5 & $>0,05$ \\
\hline Pseudomonas ae & & 2 & 0,4 & 1 & 0,3 & 1 & 0,5 & $>0,05$ \\
\hline Klehsiella & pneumoniae & 10 & 2,0 & 5 & 1,6 & 5 & 2,5 & $>0,05$ \\
\hline Klebslella & oxytoca & 3 & 0,6 & 1 & 0,3 & 2 & 1,0 & $>0,05$ \\
\hline M. pneumoniae & & 1 & 0,2 & 1 & 0,3 & 0 & 0 & $>0,05$ \\
\hline C. pneumoniae & & 1 & 0,2 & 1 & 0,3 & 0 & 0 & $>0,05$ \\
\hline
\end{tabular}

Примечание: $\mathrm{n}$ - количество наблюдений; р - статистическая значимость различий в группах SARS-CoV-2 «+» и SARS-CoV-2 «-».

Note: $n$ is the number of observations; $\mathrm{p}$ - statistical significance of differences in groups SARS-CoV-2 «+» and SARS-CoV-2 «-».

в спектре вирусных или бактериальных этиологических агентов в зависимости от продолжительности болезни. В то же время у пациентов с отрицательным результатом на SARS-CoV-2 обнаружен более широкий спектр представителей патогенной и условно-патогенной бактериальной микрофлоры во всех возрастных группах. Также наблюдалось увеличение числа внебольничных пневмоний, вызванных пневмококком, в возрастных группах старше 40 лет. Доля пациентов с микст-инфекцией достоверно не отличалась среди пациентов, находящихся на амбулаторном и стационарном лечении (соответственно
$58,3$ и $58,5 \% ; \mathrm{p}>0,05)$.

Таким образом, проведенное исследование показало, что на фоне иммуносупрессии, вызванной коронавирусной инфекцией, организм человека становится уязвимым для активизации условно-патогенной микрофлоры и развития вторичных осложнений бактериального или вирусного генеза.

В период распространения новой коронавирусной инфекции в Ростовской области основным этиологическим агентом внебольничных пневмоний является новый коронавирус SARS-CoV-2. Особенностью ВП у пациентов с лабораторно под- 
твержденным COVID-19 является более высокая частота микст-инфекций как вирусной, так и бактериальной этиологии.

На фоне выявления у пациентов с ВП РНК SARS-CoV-2 зарегистрированы случаи обнаружения коронавирусов других типов (HKU-1, OC43, HL-63 или 229E).

Наиболее часто этиологическим агентом ВП бактериальной природы являлись бактерии рода Streptococcus как у пациентов с ВП, ассоциированной с COVID-19, так и пациентов с отрицательным результатом на SARS-CoV-2.

Коронавирусные больные представляют группу высокого риска по развитию микотических поражений легких, возможно, на фоне лечения антибактериальными препаратами.

Конфликт интересов. Авторы подтверждают отсутствие конфликта финансовых/нефинансовых интересов, связанных с написанием статьи.

\section{Список литературы}

1. Чучалин А.Г., Синопальников А.И., Козлов Р.С., Авдеев С.Н., Тюрин И.Е., Руднов В.А., Рачина С.А., Фесенко О.В. Клинические рекомендации по диагностике, лечению и профилактике тяжелой внебольничной пневмонии у взрослых. Клиническая микробиология и антимикробная химиотерапия. 2015; 17(2):84-126.

2. Рачина С.А., Бобылев А.А. Атипичные возбудители внебольничной пневмонии: от эпидемиологии к особенностям диагностики и лечения. Практическая пульмонология. 2016; 2:20-7.

3. Рачина С.А., Иванчик Н.В., Козлов Р.С. Особенности микробиологической диагностики при внебольничной пневмонии у взрослых. Практическая пульмонология. 2016; 4:40-7.

4. Du Toit A. Measles increases the risk of other infections. Nat. Rev. Microbiol. 2019; 18(1):2. DOI: 10.1038/s41579-019-0301-7.

5. Zahariadis G., Gooley T.A., Ryall P., Hutchinson C. Latchford M.I., Fearon M.A., Jamieson F.B., Richardson S., Kuschak T., Mederski B. Risk of ruling out severe acute respiratory syndrome by ruling in another diagnosis: variable incidence of atypical bacteria coinfection based on diagnostic assays. Can. Respir. J. 2006; 13(1): 17-22. DOI: 10.1155/2006/862797.

6. Arabi Y.M., Al-Omari A., Mandourah Y., Al-Hameed F., Sindi A.A., Alraddadi B., Shalhoub S., Almotairi A., Al Khatib K., Abdulmomen A., Qushmaq I., Mady A., Solaiman O., Al-Aithan A.M., Al-Raddadi R., Ragab A., Al Mekhlafi G.A., Al Harthy A., Kharaba A., Ahmadi M.A., Sadat M., Mutairi H.A., Qasim E.A., Jose J., Nasim M., Al-Dawood A., Merson L., Fowler R., Hayden F.G., Balkhy H.H. Critically ill patients with the Middle East respiratory syndrome: a multicenter retrospective cohort study. Crit. Care Med. 2017; 45:1683-95. DOI: 10.1097/CCM.0000000000002621.

7. Zhou Y., Guo S., He Y., Zuo Q., Liu D., Xiao M., Fan J., Li X. COVID-19 is distinct from SARS-CoV-2-negative community-acquired pneumonia. Front. Cell. Infect. Microbiol. 2020; 10:322. DOI: $10.3389 /$ fcimb.2020.00322.

8. Lai C.-C., Wang C.-Y., Hsueh P.-R. Co-infections among patients with COVID-19: The need for combination therapy with non-anti-SARS-CoV-2 agents? J. Microbiol. Immunol. Infect. 2020; 53(4):505-12. DOI: 10.1016/j.jmii.2020.05.013.

9. Chen N., Zhou M., Dong X., Qu J., Gong F., Han Y., Qiu Y., Wang J., Liu Y., Wei Y., Xia J., Yu T., Zhang X., Zhang L. Epidemiological and clinical characteristics of 99 cases of 2019 novel coronavirus pneumonia in Wuhan, China: a descriptive study. Lancet. 2020; 395(10223):507-13. DOI: 10.1016/S0140-6736(20)30211-7.

10. Стулова М.В., Кудряшева И.А., Полунина О.С., Черенова Л.П., Аршба Т.Е., Лисина О.А., Казакова Е.А. Сравнительный клинико-лабораторный анализ COVID-19 ассоциированной пневмонии с внебольничной пневмонией бактериальной этиологии. Современные проблемы науки и образования. 2020; 3. DOI: $10.17513 /$ spno.29905.

\section{References}

1. Chuchalin A.G., Sinopalnikov A.I., Kozlov R.S., Avdeev S.N., Tyurin I.E., Rudnov V.A., Rachina S.A., Fesenko O.V. [Community-acquired pneumonia in adults: practical recommendations for diagnosis, treatment and prevention. Manual for doctors]. Klinicheskaya Mikrobiologia i Antimikrobnaya Khemoterapia
[Clinical Microbiology and Antimicrobial Chemotherapy]. 2010; 12(3):186-225.

2. Rachina S.A., Bobylev A.A. [Atypical pathogens of community-acquired pneumonia: from epidemiology to features of diagnosis and treatment]. Prakticheskaya Pulmonologia [Practical Pulmonology]. 2016; 2:20-7.

3. Rachina S.A.., Ivanchik N.V., Kozlov R.S. [Features of microbiological diagnostics in community-acquired pneumonia in adults]. Prakticheskaya Pulmonologia [Practical Pulmonology]. 2016; 4:40-7.

4. Du Toit A. Measles increases the risk of other infections. Nat. Rev. Microbiol. 2019; 18(1):2. DOI: 10.1038/s41579-019-0301-7.

5. Zahariadis G., Gooley T.A., Ryall P., Hutchinson C., Latchford M.I., Fearon M.A., Jamieson F.B., Richardson S., Kuschak T., Mederski B. Risk of ruling out severe acute respiratory syndrome by ruling in another diagnosis: variable incidence of atypical bacteria coinfection based on diagnostic assays. Can. Respir. J. 2006; 13(1):17-22. DOI: $10.1155 / 2006 / 862797$.

6. Arabi Y.M., Al-Omari A., Mandourah Y., Al-Hameed F., Sindi A.A., Alraddadi B., Shalhoub S., Almotairi A.., Al Khatib K., Abdulmomen A., Qushmaq I., Mady A., Solaiman O., Al-Aithan A.M., Al-Raddadi R., Ragab A., Al Mekhlafi G.A., Al Harthy A., Kharaba A., Ahmadi M.A., Sadat M., Mutairi H.A., Qasim E.A., Jose J., Nasim M., Al-Dawood A., Merson L., Fowler R., Hayden F.G., Balkhy H.H. Critically ill patients with the Middle East respiratory syndrome: a multicenter retrospective cohort study. Crit. Care Med. 2017; 45:1683-95. DOI: 10.1097/CCM.0000000000002621.

7. Zhou Y., Guo S., He Y., Zuo Q., Liu D., Xiao M., Fan J., Li X. COVID-19 is distinct from SARS-CoV-2-negative community-acquired pneumonia. Front. Cell. Infect. Microbiol. 2020; 10:322. DOI: $10.3389 /$ fcimb.2020.00322.

8. Lai C.-C., Wang C.-Y., Hsueh P.-R. Co-infections among patients with COVID-19: The need for combination therapy with non-anti-SARS-CoV-2 agents? J. Microbiol. Immunol. Infect. 2020; 53(4):505-12. DOI: 10.1016/j.jmii.2020.05.013.

9. Chen N., Zhou M., Dong X., Qu J., Gong F., Han Y., Qiu Y., Wang J., Liu Y., Wei Y., Xia J., Yu T., Zhang X., Zhang L. Epidemiological and clinical characteristics of 99 cases of 2019 novel coronavirus pneumonia in Wuhan, China: a descriptive study. Lancet. 2020; 395(10223):507-13. DOI: 10.1016/S0140-6736(20)30211-7.

10. Stulova M.V., Kudryasheva I.A., Polunina O.S., Cherenova L.P., Arshba T.E., Lisina O.A., Kazakova E.A. [Comparative clinical and laboratory analysis of COVID-19 associated pneumonia with community-acquired pneumonia of bacterial etiology]. Sovremennyye Problemy Nauki i Obrazovaniya [Modern Problems of Science and Education]. 2020; 3. DOI: 10.17513/spno.29905.

\section{Authors:}

Popova A.Yu., Demina Yu.V. Federal Service for Surveillance in the Sphere of Consumers Rights Protection and Human Welfare; 18, Bld. 5 and 7, Vadkovsky Pereulok, Moscow, 127994, Russian Federation. Russian Medical Academy of Continuing Professional Education; 2/1, Barrikadnaya St., Moscow, 125993, Russian Federation.

Ezhlova E.B. Federal Service for Surveillance in the Sphere of Consumers Rights Protection and Human Welfare. 18, Bld. 5 and 7 , Vadkovsky Pereulok, Moscow, 127994, Russian Federation.

Noskov A.K., Chemisova O.S., Pavlovich N.V., Vodopyanov S.O. Tsimbalistova M.V., Gaevskaya N.E. Volovikova S.V., Stenina S.I., Gudueva E.N., Sagakyants M.M. Rostov-on-Don Research Anti-Plague Institute. 117/40, M. Gor kogo St., Rostov-on-Don, 344002, Russian Federation. E-mail: plague@aaanet.ru.

Kovalev E.V., Slis'S.S. Rospoptrebnadzor Administration in the Rostov Region. 17, $18^{\text {th }}$ Line, Rostov-on-Don, 344109, Russian Federation. E-mail: master@61.rospotrebnadzor.ru.

Tverdokhlebova T.I., Aleshukina A.V. Rostov Research Institute of Microbiology and Parasitology. Rostov-on-Don, Russian Federation.

\section{Об авторах:}

Попова А.Ю., Демина Ю.В. Федеральная служба по надзору в сфере защиты прав потребителей и благополучия человека; Российская Федерация, 127994, Москва, Вадковский переулок, дом 18, строение 5 и 7. Российская медицинская академия непрерывного профессионального образования; Российская Федерация, 125993, Москва, ул. Баррикадная, 2/1.

Ежлова Е.Б. Федеральная служба по надзору в сфере защиты прав потребителей и благополучия человека. Российская Федерация, 127994 Москва, Вадковский переулок, дом 18, строение 5 и 7.

Носков А.К., Чемисова О.С., Павлович Н.В., Водопьянов С.О., Цимбалистова М.В., Гаевская Н.Е., Воловикова С.Ф., Стенина С.И., Гудуева E.H., Сагакянц М.M. Ростовский-на-Дону научно-исследовательский противочумный институт. Российская Федерация, 344002 , Ростов-на-Дону, ул. М. Горького, 117/40. E-mail: plague@aaanet.ru.

Ковалев Е.В., Слись С.С. Управление Роспотребнадзора по Ростовской области. Российская Федерация, Ростов-на-Дону, 344109, ул. 18-я линия, 17. E-mail: master@61.rospotrebnadzor.ru.

Твердохлебова Т.И., Алешукина А.В. Ростовский научно-исследовательский институт микробиологии и паразитологии. Российская Федерация, Ростов-на-Дону. 